\title{
Tetrahydrocurcumin protection against doxorubicin-induced apoptosis
}

\author{
Nuntiya Somparn $^{\mathrm{a}, *}$, Veerapol Kukongviriyapan ${ }^{\mathrm{b}}$, Upa Kukongviriyapan $^{\mathrm{c}}$, Laddawan Senggunprai ${ }^{\mathrm{b}}$, \\ Auemduan Prawan ${ }^{\mathrm{b}}$ \\ a Division of Pharmacology, Preclinical Science, Faculty of Medicine, Thammasat University, Thailand \\ b Department of Pharmacology, Faculty of Medicine, Khon Kaen University, Khon Kaen, Thailand \\ c Department of Physiology, Faculty of Medicine, Khon Kaen University, Khon Kaen, Thailand
}

*Corresponding author, e-mail: nuntiya_tom@hotmail.com

Received 16 Sep 2014

Accepted 17 May 2015

\begin{abstract}
Tetrahydrocurcumin (THC), an active metabolite of curcumin, possesses potent antioxidant activity and is more stable in vivo than curcumin. We investigated the protective effect of THC on doxorubicin (DOX)-induced apoptotic cell death in association with the dissipation of the mitochondrial membrane potential using cholangiocyte MMNK-1 cell lines. Exposure to DOX (0.3-3 $\mu \mathrm{M}$ for $24 \mathrm{~h})$ induced cell death in a dose-dependent manner. Pre-treatment with THC (1, 3, $6 \mu \mathrm{M})$ for $24 \mathrm{~h}$ significantly increased cell survival. To determine the THC cytoprotective mechanism, intracellular superoxide anion levels and mitochondrial transmembrane potential were measured. Exposure to DOX increased intracellular superoxide anions in the cells. The superoxide levels were significantly reduced when the cells were pretreated with THC, implying the presence of antioxidant activity in THC. Moreover, DOX-induced dissipation of the mitochondrial membrane potential was alleviated by pre-treatment with THC. The results suggest that THC induces a cytoprotective effect that maintains mitochondrial function and suppresses the formation of reactive-oxygen species.
\end{abstract}

KEYWORDS: mitochondrial transmembrane potential, antioxidant

\section{INTRODUCTION}

Curcumin (CUR), a phenolic compound from Curcuma longa, possesses several pharmacological activities including anti-inflammatory, antioxidant, and anticancer ${ }^{1}$. In common with several other dietary-derived polyphenol compounds, curcumin has a low systemic bioavailability. CUR absorbs poorly, particularly in humans, limiting its clinical utility.

Tetrahydrocurcumin (THC), a colourless derivative of CUR and one of the major metabolites of CUR, contains antioxidant and chemopreventive activities suitable for pharmaceutical applications. THC exhibits physiological and pharmacological properties such as a cardiovascular protective role against oxidative stress similar to that of CUR at the same doses in vivo. THC probably has better oral bioavailability and may be a better antioxidant in vivo than CUR $^{2}$. Moreover, THC is more stable than CUR both in vivo and in vitro ${ }^{3}$. The protective effect of THC however has not yet been evaluated in an experimental setting of a chemically induced mitochondrial dysfunction, as mitochondria perform the tasks of inducing apoptosis and programmed cell death, cellular calcium balance, and redox homoeostasis.

Doxorubicin (DOX), an anthracycline drug most widely applied in the chemotherapy of various cancers, is a potent pro-oxidant ${ }^{4}$. DOX produces cytotoxicity by undergoing redox cycling and reacts with enzymes of mitochondrial respiration. Mitochondria are considered to be one of the primary targets of DOX through mitochondria-mediated apoptosis, a remarkable modification of mitochondrial membranes, which is also associated with changes in various mitochondrial functional parameters and activities of the respiratory chain complexes ${ }^{5}$. Thus we investigated the cytoprotective effect of THC on the mitochondrial function evaluated by measuring mitochondrial transmembrane potential $\left(\Delta \Psi_{\mathrm{m}}\right)$ changes by DOX in cholangiocyte $M M N K-1$ cell lines.

\section{MATERIALS AND METHODS}

\section{Cell culture}

MMNK-1 cells were routinely cultured in Ham's F12 media supplemented with $12.5 \mathrm{mM}$ $\mathrm{N}$-2-hydroxyethylpiperazine- NO-2-ethanesulphonic acid (HEPES) (pH 7.3), $100 \mathrm{U} / \mathrm{ml}$ penicillin, 
100 unit/ml streptomycin sulphate and 10\% fetal calf serum as previously described ${ }^{6}$. The cells were subcultured every 2-3 days before the confluence of the cells using $0.25 \%$ trypsin-EDTA, and the medium was renewed after an overnight incubation.

\section{Test compounds}

THC of purity $>99 \%$, by HPLC was kindly supplied from the Research and Development Institute, Government Pharmaceutical Organization, Thailand. This compound has been used in the previous publications by our group.

\section{Sulforhodamine B assay}

MMNK-1 cells were seeded onto 96-well culture plates at a density of $5 \times 10^{3}$ cells/well. After an overnight culture, the cells were pre-treated with THC 1-6 $\mu \mathrm{M}$ for $24 \mathrm{~h}$ followed by exposure to $0.3-$ $3 \mu \mathrm{M}$ DOX for another $24 \mathrm{~h}$. Cytotoxicity was determined by sulforhodamine B (SRB) colorimetric assay. Briefly, the cells were washed by phosphatebuffered saline (PBS) and fixed with 10\% (w/v) trichloroacetic acid, and stained with $0.4 \%$ SRB in $1 \%$ acetic acid for $30 \mathrm{~min}$. After that the excess dye was removed by washing repeatedly with $1 \%(\mathrm{v} / \mathrm{v})$ acetic acid. The protein-bound dye was dissolved in $10 \mathrm{mM}$ Tris base solution $\mathrm{pH} 10.5$ and incubated for $20 \mathrm{~min}$. The absorbance was determined at $540 \mathrm{~nm}$ using a microplate reader.

\section{Acridine orange and ethidium bromide assay}

To identify apoptotic cells, cultured cells were stained with fluorescent dyes as previously described with modifications ${ }^{7}$. In brief, the medium was removed after an experiment and replaced with PBS. The cells were then stained in the dark with acridine orange and ethidium bromide (AO/EB) dissolved in PBS. The cells were examined using a Nikon Eclipse TS100 inverted microscope with excitation and long-pass emission filters of $480 \mathrm{~nm}$ and $535 \mathrm{~nm}$, respectively. Fluorescent images were taken at two predetermined areas in each well with triplicate wells per concentration using a Nikon Coolpix digital camera. The viable, apoptotic, and necrotic cells were counted. Viable cells appeared stained with green fluorescence and intact nuclei; apoptotic cells appeared with green fluorescence, cell shrinkage, and nuclear condensation and fragmentation; necrotic cells appeared with a bright orange fluorescence. The apoptotic cells were calculated as the percent apoptotic cells over a total number of cells in the same area.

\section{Determination of superoxide formation}

Generations of reactive oxygen species and mitochondrial dysfunction has been implicated in doxorubicin-induced toxicity. The intracellular production of reactive-oxygen species (ROS) was monitored by the lucigenin-enhanced chemiluminescence method according to the previously described method $^{6}$. In brief, MMNK-1 cells were cultured in $35-\mathrm{mm}$ dishes overnight. The cell cultures were then washed and replaced with fresh media supplemented with THC $3 \mu \mathrm{M}$ for $24 \mathrm{~h}$, followed by exposure to DOX $1 \mu \mathrm{M}$ for another $3 \mathrm{~h}$. Subsequently, the cultures were washed with PBS, and superoxide formation was measured using lucigenin as a substrate with a luminometer (Model 20/20n, Turner Biosystem).

\section{Measurement of mitochondrial transmembrane potential}

The dissipation of the mitochondrial electrochemical potential gradient is known as an early event leading to apoptosis. To measure the change in $\Delta \Psi_{\mathrm{m}}$, cells were seeded in 96 black well plates at a density of 10000 cells/well and cultured overnight before treatment with THC $3 \mu \mathrm{M}$ for $24 \mathrm{~h}$ followed by exposure to DOX $1 \mu \mathrm{M}$ for another $1 \mathrm{~h}$. The assay was performed according to the method described previously ${ }^{8}$ using the cationic, lipophilic dye, 5,5',6,6'-tetrachloro-1, $1^{\prime}, 3,3^{\prime}$ tetraethyl-benzimidazolyl carbocyanine iodide (JC-1) (Clayman chemical) staining with some modifications, i.e., reducing the the number of culture cells in a 96-well black plate to a density of $1.5 \times 10^{4}$ cells/well in $100 \mu \mathrm{l}$ culture medium. The cultured plate was centrifuged at $400 \mathrm{~g}$ for $5 \mathrm{~min}$ at room temperature. The cultured medium was then removed, loaded with JC-1 dye for $20 \mathrm{~min}$, washed by centrifugation and incubated in the assay buffer. Finally, the $\Delta \Psi_{\mathrm{m}}$ was determined under a fluorescent microscope with an excitation wavelength of $485 \mathrm{~nm}$ and emission wavelength of $535 \mathrm{~nm}$. JC-1 forms Jaggregates in a healthy mitochondrial matrix, which can be visualized as red fluorescence. In depolarized mitochondria, JC-1 diffuses to the cytoplasm and exists as monomers with green fluorescence. The shift of red to green fluorescence is an indicative of the depolarization of $\Delta \Psi_{\mathrm{m}}$. To perform a quantitative analysis of the membrane potential, the cells staining with fluorescent probe were selected and the intensity of red and green fluorescent channels analysed. The results are presented as the ratio of red and green fluorescence. 


\section{Statistical analysis}

Data are presented as mean \pm SEM. An ANOVA with Duncan post-hoc test was used to determine significant differences between each experimental group. An ANOVA on-rank test was also performed for the non-parametric test. The level of significance was set at $p<0.05$.

\section{RESULTS}

\section{Cytoprotective effect of tetrahydrocurcumin against DOX-induced cell death}

To evaluate the effect of THC on chemical toxicants, MMNK-1 cells were pretreated with THC at varied concentrations for $24 \mathrm{~h}$ and the cytotoxicity was induced by the addition of DOX at varied concentrations for another $24 \mathrm{~h}$ before assay of cytotoxicity.

Treatment with THC 1-6 $\mu \mathrm{M}$ alone for $24 \mathrm{~h}$ did not affect cell viability. Exposure to DOX results in cell death in a dose-dependent manner. At high DOX concentrations, about $75 \%$ of the cells died. Pre-treatment with THC significantly increased cell survival up to 2 fold at high dose of DOX, when compared to DOX-treated controls. The induction of apoptotic cell death was analysed by AO/EB assay. In Fig. 1, the number of viable cells, apoptotic cells and necrotic cells were counted. DOX-induced apoptotic and necrotic cell death was partially inhibited by THC (Fig. 1a-c). This result was consistent with the cell viability measured by the SRB assay.

\section{THC suppresses superoxide-anion formation}

DOX has been suggested to induce cell death via generation of superoxide anions. MMNK-1 cells were incubated with THC for $24 \mathrm{~h}$, followed by a treatment with DOX for another $3 \mathrm{~h}$. DOX alone induced a large amount of superoxide formation. DOX-induced ROS was significantly reduced in cells pre-treated with THC to the basal level. Treatment with THC alone did not cause increased formation of ROS. These results indicate an antioxidant activity of THC. Inhibition of superoxide anion may be a part of the cytoprotective mechanisms of the compounds.

\section{THC-ameliorated DOX-induced dissipation of the mitochondrial transmembrane potential}

In untreated control cells, mitochondria predominantly exhibited red fluorescence because of an accumulation of J-aggregates representing the intact $\Delta \Psi_{\mathrm{m}}$. DOX treatment rapidly depolarized $\Delta \Psi_{\mathrm{m}}$, as shown by the green fluorescence of JC-1 monomeric forms present in the cytosol (Fig. 2a). The ratio

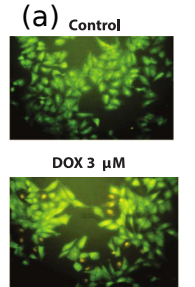

(c)

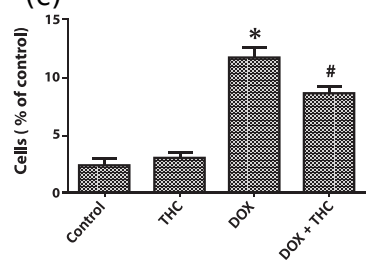

(b)

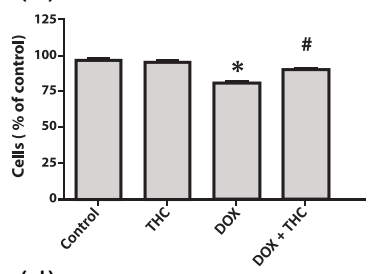

(d)

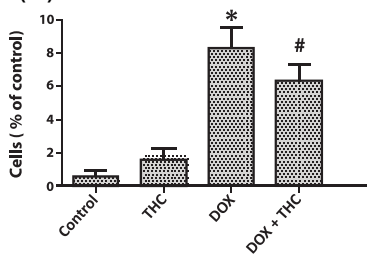

Fig. 1 The protective effects of THC against DOX-induced apoptosis. (a) Fluorescent images of cultured cells with AO/EB staining. (b) The number of normal cells, (c) the number of apoptotic cells, (d) the number of necrotic cells. MMNK-1 cells were pretreated with varied concentrations of THC $6 \mu \mathrm{M}$ for $24 \mathrm{~h}$ followed by treatment with $3 \mu \mathrm{M}$ of DOX for another $24 \mathrm{~h}$. The apoptotic cells were calculated as the percent apoptotic cells over the total number of cells in the same area. Each bar represents the mean \pm SEM from three experiments; * $p<0.05$ compared with normal control; ${ }^{*} p<0.05$ compared with DOX treated.

of J-aggregation/monomer is represented by red/green fluorescence (Fig. 2b). The effect was apparent within the first hour of incubation. The effects of THC on the DOX-induced $\Delta \Psi_{\mathrm{m}}$ changes were evaluated. As was expected, THC ameliorated the depolarization of $\Delta \Psi_{\mathrm{m}}$ in MMNK-1 cell lines and exhibited more red fluorescence from accumulation of J-aggregates representing the intact $\Delta \Psi_{\mathrm{m}}$ as compared with DOX treatment alone.

Pre-treatment with THC (1-6 $\mu \mathrm{M})$ significantly increased cell survival up to $85 \%$, when compared to DOX (0.1-3 $\mu \mathrm{M})$ treated controls. This result was also correlated with the quantification of alive, necrotic, and apoptotic cells in MMNK-1 cells pretreated with THC followed by treatment with $3 \mu \mathrm{M}$ of DOX (Fig. 1a-c). Thus comparable results, including inhibiting superoxide generation and maintaining the integrity of mitochondrial membrane potential, were obtained in MMNK-1 cell treated with high dose $(3 \mu \mathrm{M})$ of doxorubicin.

\section{DISCUSSION}

THC is one of the colourless biotransformed products of curcumin. In human and rat hepatocytes, curcumin is rapidly metabolized into THC and other 
(a)

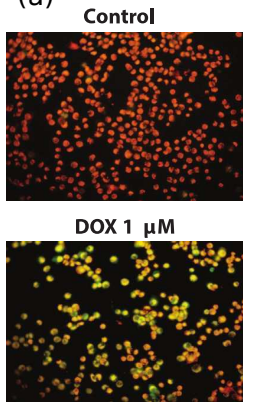

THC $3 \mu \mathrm{M}$

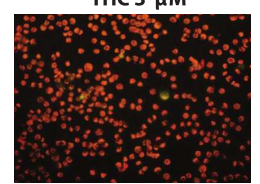

DOX $1 \mu \mathrm{M}+\mathrm{THC} 3 \mu \mathrm{M}$

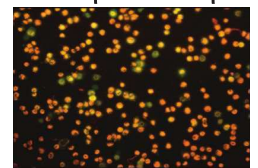

THC $6 \mu \mathrm{M}$

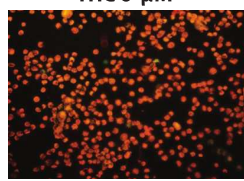

DOX $1 \mu \mathrm{M}+\mathrm{THC} 6 \mu \mathrm{M}$

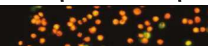

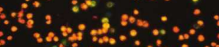

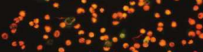

(b)

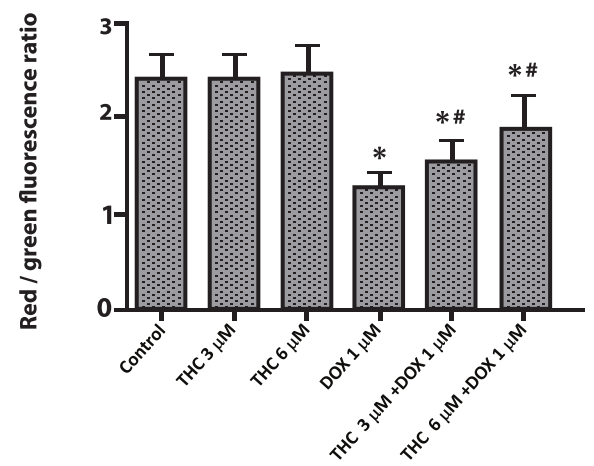

Fig. 2 THC-ameliorated DOX-induced dissipation of the mitochondrial transmembrane potential. (a) Fluorescent images of cultured cells with the JC-1 staining. (b) The ratio of red and green fluorescence. Cells were treated with 3 or $6 \mu \mathrm{M}$ of THC for $24 \mathrm{~h}$ followed by $1 \mu \mathrm{M}$ DOX for $1 \mathrm{~h}$. The change in $\Delta \Psi_{\mathrm{m}}$ was examined using the JC-1 staining method. The fluorescent images of cultured cells were captured. The cells staining with fluorescent probe were selected and analysed the intensity of red and green fluorescent channels. The result is presented as the ratio of red and green fluorescence, each calculated from 8 images of two experiments with similar results; representative images from one experiment were shown; * significantly different from control group; \# significantly different from DOX-treated group.

reduced forms ${ }^{9}$. The structures of both curcumin and THC show that they have $\beta$-diketone moiety and a phenolic group, which are believed to exhibit antioxidative activity ${ }^{10}$. THC exhibits pharmacological properties similar to its precursor, including antioxidant effects ${ }^{11}$ and induction of the activity of antioxidant enzymes ${ }^{12}$. Moreover, THC is more stable than CUR, which may be an advantage over CUR. In this present study, THC exhibited a cytoprotective effect in association with suppression of ROS formation and maintenance of $\Delta \Psi_{\mathrm{m}}$.

Generations of reactive oxygen species and mitochondrial dysfunction have been implicated in

doxorubicin-induced toxicity. Navarro et al determined the possible involvement of particular free radicals in DOX-induced ERK phosphorylation with subsequent induction of apoptotic cell death ${ }^{13}$. They concluded that superoxide anions, probably generated by DOX metabolism, are involved in the effects of the anthracycline on the MAP kinase cascade activation. Hence this study focused on the superoxide production. As expected, we found that DOX treatment resulted in a significant increase in the intracellular superoxide-anion production and this result was associated with mitochondria dysfunction and cytotoxicity in MMNK-1 cells. Treatment with THC prevented and disrupted the DOX-generated superoxide anion and ameliorated DOX-induced dissipation of $\Delta \Psi_{\mathrm{m}}$.

In this study, we also found that treatment with THC at concentration 1-6 $\mu \mathrm{M}$ for $24 \mathrm{~h}$ did not cause cell death, but exhibited a protective effect. As THC has no pro-oxidant activity, THC treatment alone did not induce ROS formation. The ROS scavenging effect of THC may be a direct and indirect antioxidant effect of THC. THC exerts its effective antioxidant activity by scavenging free radicals its indirect antioxidant activity by inducing of the activity of antioxidant enzymes ${ }^{12}$. A recent comparative study of the antioxidant activities of curcumin and THC has indicated that the scavenging activity of THC was significantly greater than that of curcumin, using the 2,2'-diphenyl-1-picrylhydrazyl radical and 2,2'-azobis(2-aminopropane) dihydrochloride (AAPH)-induced red blood cell haemolysis assay ${ }^{14}$. Beside its radical scavenging activity, THC induces antioxidant enzymes, such as glutathione peroxidase, glutathione S-transferase, and $\mathrm{NADPH}^{2}$. In addition, THC alleviates oxidative stress by increasing blood glutathione (GSH) and the redox ratios of GSH in treated L-NAME hypertensive rats ${ }^{15}$. Using rat primary hippocampal cultures, THC shows a protective effect against oligomeric amyloid- $\beta$-induced toxicity by reducing the level of ROS and increase in mitochondrial membrane potential ${ }^{16}$.

The $\Delta \Psi_{\mathrm{m}}$ is maintained by the respiratory chain complexes to generate ATP. Disturbance of the $\Delta \Psi_{\mathrm{m}}$ results in cellular energy crisis with subsequent initiation of cell death ${ }^{17}$. It is, therefore, mitochondria that plays central function in live and death. DOX-induced cell death is associated with mitochondrial respiratory chain defects manifested as mitochondrial redox state shifts, ROS production, and decrease in mitochondrial $\Delta \Psi_{\mathrm{m}}{ }^{18}$. Thus ROS formation and $\Delta \Psi_{\mathrm{m}}$ considered as functional biomarkers for DOX-induced cell death. In this 
study, THC has showed to maintain the integrity of $\Delta \Psi_{\mathrm{m}}$, by a mechanism associated with suppression of ROS formation.

In conclusion, our data suggest that THC provides a cytoprotective effect against DOX-induced cytotoxicity. This effect may be attributable to many factors, including the ability to scavenge free radicals and to ameliorate DOX-induced mitochondrial dysfunction. The underlying mechanism of THC on mitochondrial function however needs further investigation. THC may be a good candidate as a cytoprotective against oxidant-induced cell death.

Acknowledgements: This work was supported by a grant from Thailand Research Fund (MRG 5480202) and the Faculty of Medicine, Thammasat University, Thailand. Tetrahydrocurcumin, generous gifts were gratefully received from Praphassorn Surawattanawan, $\mathrm{PhD}$, of the Research and Development Institute, Government Pharmaceutical Organization, Bangkok, Thailand.

\section{REFERENCES}

1. López-Lázaro M (2008) Anticancer and carcinogenic properties of curcumin: Considerations for its clinical development as a cancer chemopreventive and chemotherapeutic agent. Mol Nutr Food Res 52, Suppl 1, S103-27.

2. Okada K, Wangpoengtrakul C, Tanaka T, Toyokuni S, Uchida K, Osawa T (2001) Curcumin and especially tetrahydrocurcumin ameliorate oxidative stress-induced renal injury in mice. $J$ Nutr 131 , 2090-5.

3. Pan MH, Huang TM, Lin JK (1999) Biotransformation of curcumin through reduction and glucuronidation in mice. Drug Metabol Dispos 27, 486-94.

4. Nayak PG, Paul P, Bansal P, Kutty NG, Pai KS (2013) Sesamol prevents doxorubicin-induced oxidative damage and toxicity on H9c2 cardiomyoblasts. J Pharm Pharmacol 65, 1083-93.

5. Childs AC, Phaneuf SL, Dirks AJ, Phillips T, Leeuwenburgh C (2002) Doxorubicin treatment in vivo causes cytochrome $\mathrm{C}$ release and cardiomyocyte apoptosis, as well as increased mitochondrial efficiency, superoxide dismutase activity, and Bcl-2:Bax ratio. Canc Res 62, 4592-8.

6. Prawan A, Buranrat B, Kukongviriyapan U, Sripa B, Kukongviriyapan V (2009) Inflammatory cytokines suppress $\mathrm{NAD}(\mathrm{P}) \mathrm{H}$ :quinone oxidoreductase- 1 and induce oxidative stress in cholangiocarcinoma cells. $J$ Canc Res Clin Oncol 135, 515-22.

7. Buranrat B, Prawan A, Kukongviriyapan U, Kongpetch S, Kukongviriyapan V (2010) Dicoumarol enhances gemcitabine-induced cytotoxicity in high NQO1-expressing cholangiocarcinoma cells. World $J$ Gastroenterol 16, 2362-70.
8. Kongpetch S, Kukongviriyapan V, Prawan A, Senggunprai L, Kukongviriyapan U, Buranrat B (2012) Crucial role of heme oxygenase- 1 on the sensitivity of cholangiocarcinoma cells to chemotherapeutic agents. PLoS ONE 7, e34994.

9. Ireson C, Orr S, Jones DJ, Verschoyle R, Lim CK, Luo JL, Howells L, Plummer S, et al (2001) Characterization of metabolites of the chemopreventive agent curcumin in human and rat hepatocytes and in the rat in vivo, and evaluation of their ability to inhibit phorbol ester-induced prostaglandin E2 production. Canc Res 61, 1058-64.

10. Priyadarsini KI, Maity DK, Naik GH, Kumar MS, Unnikrishnan MK, Satav JG, Mohan H (2003) Role of phenolic $\mathrm{O}-\mathrm{H}$ and methylene hydrogen on the free radical reactions and antioxidant activity of curcumin. Free Radic Biol Med 35, 475-84.

11. Somparn P, Phisalaphong C, Nakornchai S, Unchern S, Morales NP (2007) Comparative antioxidant activities of curcumin and its demethoxy and hydrogenated derivatives. Biol Pharmaceut Bull 30, 74-8.

12. Pari L, Murugan P (2007) Tetrahydrocurcumin prevents brain lipid peroxidation in streptozotocininduced diabetic rats. J Med Food 10, 323-9.

13. Navarro R, Busnadiego I, Ruiz-Larrea MB, RuizSanz JI (2006) Superoxide anions are involved in doxorubicin-induced ERK activation in hepatocyte cultures. Ann New York Acad Sci 1090, 419-28.

14. Sugiyama Y, Kawakishi S, Osawa T (1996) Involvement of the beta-diketone moiety in the antioxidative mechanism of tetrahydrocurcumin. Biochem Pharmacol 52, 519-25.

15. Nakmareong S, Kukongviriyapan U, Pakdeechote P, Donpunha W, Kukongviriyapan V, Kongyingyoes B, Sompamit K, Phisalaphong C (2011) Antioxidant and vascular protective effects of curcumin and tetrahydrocurcumin in rats with L-NAME-induced hypertension. N Schmied Arch Pharmacol 383, 519-29.

16. Mishra S, Mishra M, Seth P, Sharma SK (2011) Tetrahydrocurcumin confers protection against amyloid $\beta$-induced toxicity. NeuroReport 22, 23-7.

17. Kim JS, He L, Lemasters JJ (2003) Mitochondrial permeability transition: a common pathway to necrosis and apoptosis. Biochem Biophys Res Comm 304, 463-70.

18. Kuznetsov AV, Margreiter R, Amberger A, Saks V, Grimm M (2011) Changes in mitochondrial redox state, membrane potential and calcium precede mitochondrial dysfunction in doxorubicin-induced cell death. Biochim Biophys Acta 1813, 1144-52. 